\title{
COMPARATIVE STUDY ON THE DAILY ACTIVITY BUDGET OF SUN BEAR (Helarctus malayanus) IN CAPTIVITY AND SEMI-CAPTIVITY
}

\author{
SITI SARAYATI ABDUL MAWAH ${ }^{1,2^{*}}$, LO CHOR-WAI ${ }^{1}$ and FARNIDAH JASNIE ${ }^{1}$ \\ ${ }^{1}$ Faculty of Applied Sciences, Universiti Teknologi MARA Sabah Branch, \\ Kota Kinabalu campus, 88997, Kota Kinabalu, Sabah, Malaysia \\ ${ }^{2}$ Institute of Biological Science, Faculty of Science, University of Malaya, \\ 50603, Kuala Lumpur, Malaysia \\ *E-mail: sarayati@uitm.edu.my
}

Accepted 15 March 2021, Published online 20 May 2021

\begin{abstract}
A comparative study on the daily activity budget of the sun bear was conducted in Lok Kawi Wildlife Park and Borneon Sun Bear Conservation Centre (BSBCC) Malaysia. The behaviour of 22 individuals was recorded using the Instantaneous scan sampling method. A total of $330 \mathrm{hr}$ were collected, with $180 \mathrm{hr}$ were collected at Lok Kawi Wildlife Park and $150 \mathrm{hr}$ at BSBCC. Thirteen behavioural activities were recorded using the Ad-libitum sampling method in both captive and semicaptive bears, which were then grouped into three categories; active, passive, and abnormal behaviours classes and tabulated in an ethogram. Captive sun bears are kept permanently under human control, such as in zoos, while semi-captive sun bears are released to the forest during the day but kept in the cage at night. This study shows that semi-captive bears are significantly more active than captive bears. More passive and abnormal behaviours are present in captive bears. Stereotypic pacing scored the highest percentage of observation with $24 \%$ for abnormal behaviour in captive bears. Both captive and semi-captive bears showed a similar pattern of active and passive behavioural rhythms. The peak for active behaviours was from 1000 to $1100 \mathrm{hr}$, and the peak for passive behaviours was from 1300 to $1400 \mathrm{hr}$. In conclusion, although there was a difference in activities done between captive and semi-captive bears, the pattern of behavioural rhythms between both group of bears was similar. The introduction of enrichment programmes is crucial to captive bears to reduce stereotypic pacing behaviour.
\end{abstract}

Key words: Captive exhibit, semi-captive exhibit, sun bear, zoo behaviour

\section{INTRODUCTION}

Keeping animals in captivity, such as in zoos forming as part of a breeding programme, is one of the widely accepted approaches in the conservation management of threatened animals like the sun bear. This bear will receive veterinary care, free from starvation and predation (Clubb \& Mason, 2007). Various studies on different animal species indicate that fecundity and survival rates are generally higher in captivity than in wild populations (Robeck et al., 2015; Lahdenpera et al., 2018). However, captive animals live in an environment that is completely different from their original habitat (McPee \& Carlstead, 2010). For many captive wild species, several difficulties exist in captivity. One of the main

* To whom correspondence should be addressed. concerns for animals kept in captivity is expressing abnormal behaviour, such as stereotypical behaviour, which can be one of the indicators of poor animal welfare and often a sign of decreased animal welfare (Wolfensohn, 2018) due to their limited option to express natural behaviour (Clubb \& Mason, 2007). Mason (1991) defined stereotypical behaviour as repetitive unvarying and functionless behaviour. Stereotypic behaviour is related to stress in the captive animal, especially in the bear (Shih et al., 2016). Sun bears are usually kept in a fully captive and semi-captive environment. Captive sun bears are kept permanently under human control, such as in zoos, while semi-captive sun bears are released to the forest during the day but kept in the cage at night.

Most bear species, including sun bear kept in captivity, exhibited abnormal behaviour due to many factors, including the size of the enclosure 
(Berghammer, 2008; Tan et al., 2013). The small size of the enclosure restricts bears ability to perform their natural behaviour, such as foraging and exploring (Carlstead \& Shepherson, 2000; McPhee \& Carlstead, 2010). Besides, a barren or unexciting environment (Carlstead \& Shepherson, 2000; Morgan \& Tromborg, 2007) also contributed to such a result as the bears have less activity in their barren enclosure. Thus, it has received great attention from zoo animals' behaviour literature over several decades (Vickery \& Mason, 2005; Tan et al., 2013; Shepherdson et al., 2013). Restrictions in the ability to perform normal species-specific behaviours may lead to stress and frustration and be detrimental to their welfare because stressed bears could become aggressive and harm each other. This often manifests as alterations to behavioural patterns, such as the development of stereotypical behaviours (Mason et al., 2007).

This study aims to describe and compare the daily behavioural activity patterns and behavioural rhythms of the sun bear in two captivity types: fully captive and semi-captive exhibit with particular attention to stereotypical behaviour such as pacing. The specific objectives of this study are: (1) to determine the activity budget of both captive and semi-captive sun bears across sex and age, and (2) to determine the behavioural rhythms of sun bears in captive and semi-captive exhibits.

\section{MATERIALS AND METHODS}

\section{Study Subjects}

Sun bears were categorised into two groups: captive and semi-captive sun bears. Captive sun bears are kept permanently under human control, such as in zoos, while semi-captive sun bears are released to the forest during the day but kept in the cage at night.

The observation was carried out on seven individuals sun bear housed in Lok Kawi Wildlife Park, Kota Kinabalu, Sabah, and 15 individuals sun bear in the Borneon Sun bear Conservation Centre (BSBCC) Sabah, Malaysia. Based on the records, the bear's ages were approximately between 4 to 25 years, with three male and four female bears in Lok Kawi Wildlife Parks and seven male and eight female bears in BSBCC. Most of the animals were donated by the public, and some were rescued from the villagers who kept the bear as a pet. In Lok Kawi Wildlife Park, the bears were housed in three separate cages sized $8 \times 6 \mathrm{ft}$ for each cage when the zoo is closed and released into the enclosure each morning. The enclosure is oval-shaped with a dimension of $60 \times 40 \mathrm{ft}$, and it is enriched with three culverts, two small logs, and one small pool. The management routine included the delivery of the primary daily feeding in both of the study sites twice daily, early morning at 7:00 a.m. to 8:00 a.m., and at the end of the day at 5:00 p.m., and and thus ensuing the bears to enter the cages voluntarily when the cage doors were opened in the late afternoon at 4:30 p.m.

\section{Procedure}

\section{Behavioural Sampling Methods}

Observations were recorded for all seven bears from Lok Kawi Wildlife Park and 15 selected bears from BSBCC every day - from December 2017 to March 2018 (Lok Kawi Wildlife Park) and from September 2018 to January 2019 (BSBCC) - for 30 consecutive days at each study sites. An ethogram composed from a literature review of sun bear behaviour (Veeraselvam et al., 2013; Stokes, 2014) and modified with preliminary data collected during the pilot study using Ad Libitum sampling was used to record behavioural observations (Table 1). Observation refers to one animal behavioural activity in a scan. Therefore, in each scan, a total of seven bears' behaviour was recorded at Lok Kawi, and 15 bears' behaviour was recorded at the BSBCC. The sampling protocol consisted of Instantaneous scan sampling conducted at a 15 -min interval to record all individual activity data in two 3-hr segments each day, respectively at $0900-1200$ and $1300-1600 \mathrm{hr}$ segment times (Altmann, 1974; Amato et al., 2013). No observations were made between 1200 - $1300 \mathrm{hr}$ as the increased human-animal encounters occurring during this hour, which probably affect the bears' behaviour.

\section{Activity Budgets}

The type of behaviour was group into three categories: active, passive and abnormal behaviours classes (Table 1). Activity budgets were created for each individual and all individuals combined and compared at the study site. The analysis of activity budgets was calculated using the Mann-Whitney U tests (Bluman, 2014). Instantaneous scan sampling was conducted at 15-min intervals to record all individuals' activity data in two 3-hr segments each day, respectively at $0900-1200$ and $1300-1600 \mathrm{hr}$ segment times for 30 consecutive days from December 2017 to January 2019.

\section{Data Analysis}

Data comparing daily behavioural activity between captive and the semi-captive exhibit was analysed using the Man-Whitney U test. The MannWhitney U test was also used to compare active, passive, and abnormal behaviour between captive and semi-captive exhibit. To compare the daily activity budget between male and female, and adult and juvenile in all study sites, the Mann-Whitney U 
Table 1. Ethogram list for categories of active, passive, and abnormal behaviours in sun bear captivity study

\begin{tabular}{|c|c|}
\hline \multicolumn{2}{|r|}{ Active behaviour } \\
\hline Activities & Description \\
\hline Exploring & $\begin{array}{l}\text { Searching for things inside the enclosure like dead branches, stones, walls, artificial objects and so } \\
\text { forth }\end{array}$ \\
\hline Locomotion & Moving from one place to another inside its enclosure quadrupedally or bipedally \\
\hline Climbing & Actively moving in a vertical motion either up or down, typically associated with arboreal movement \\
\hline Digging & Making a hole on the ground with its paws and/or claw \\
\hline Social & $\begin{array}{l}\text { Interacting or engaging with another bear, including touching, chasing, playing and non-aggressive } \\
\text { wrestling/fighting }\end{array}$ \\
\hline Solitary & Playing all by itself with inanimate objects inside its enclosure \\
\hline Foraging & $\begin{array}{l}\text { Manipulating food items, including live plant material and insect found inside the enclosure, drinking } \\
\text { water; and consume food items provided by bear keepers }\end{array}$ \\
\hline \multicolumn{2}{|r|}{ Passive behaviour } \\
\hline Activities & Description \\
\hline Rest & Non-locomotion behaviour (sits or lies, stationary with eyes open) \\
\hline Sleeping & Sits or lies, stationary with eyes close \\
\hline Alert & Bear lies, sit and stand with head up and eyes open and responds to any stimuli \\
\hline Auto-grooming & $\begin{array}{l}\text { Physical hygiene including cleaning body part with its mouth and paws, scratches, examining its } \\
\text { body parts, defecate, urinate }\end{array}$ \\
\hline \multicolumn{2}{|r|}{ Abnormal behaviour (Stereotypic behaviour) } \\
\hline Activities & Description \\
\hline Pacing & Bear moving in the same path repetitively (left to right, right to the left) \\
\hline Head tossing & Moving the head up and down \\
\hline
\end{tabular}

** Modified from Veeraselvam et al., (2013) and Stokes (2014).

test was again used for analysis. For the behavioural rhythms, data on the daily behavioural pattern of the active, passive, and abnormal behaviour at all study sites were analysed using the Kruskal-Wallis test.

\section{RESULTS AND DISCUSSION}

\section{Activity Budget of Captive and Semi-Captive Bear}

During the study, a total of $330 \mathrm{hr}$ of observations were recorded for all bears from December 2017 to January 2019 using the scan sampling method. A total of $180 \mathrm{hr}$ were collected at Lok Kawi Wildlife Park, and $150 \mathrm{hr}$ were collected at BSBCC. The differences in the proportions of time allocated in three behaviour classes, made up of thirteen behaviour categories, were compared across the study site (Figure 1). From these thirteen behaviours, seven behaviours differed significantly between study sites; climbing (Mann-Whitney $t=5.10, \mathrm{DF}=15, p<0.05)$, digging $(t=4.44, \mathrm{DF}=20$, $p<0.05)$, foraging $(t=0.007, \mathrm{DF}=20, p<0.05)$, resting $(t=2.44, \mathrm{DF}=19, p<0.005)$, sleeping $(t=5.60, \mathrm{DF}=15$, $p<0.05)$, grooming $(t=3.25, \mathrm{DF}=20, p<0.05)$ and pacing $(t=4.44, \mathrm{DF}=20, p<0.05)$. Semi-captive bears allocated most of their time for foraging (25\%), exploring (20.5\%), climbing (20\%), and locomotion (18.25\%). Captive sun bears, on the other hand, spent less time foraging and invested more time resting (26.62\%), sleeping (26.44\%), and pacing (24.28\%) (Figure 1). A previous study on captive sun bears in Peninsula Malaysia concurred with this finding whereby the bears showed the most frequent resting and stereotypic pacing activities (Tan et al., 2013). This shows that semi-captive bears are more active than captive bears. However, abnormal behaviours, such 


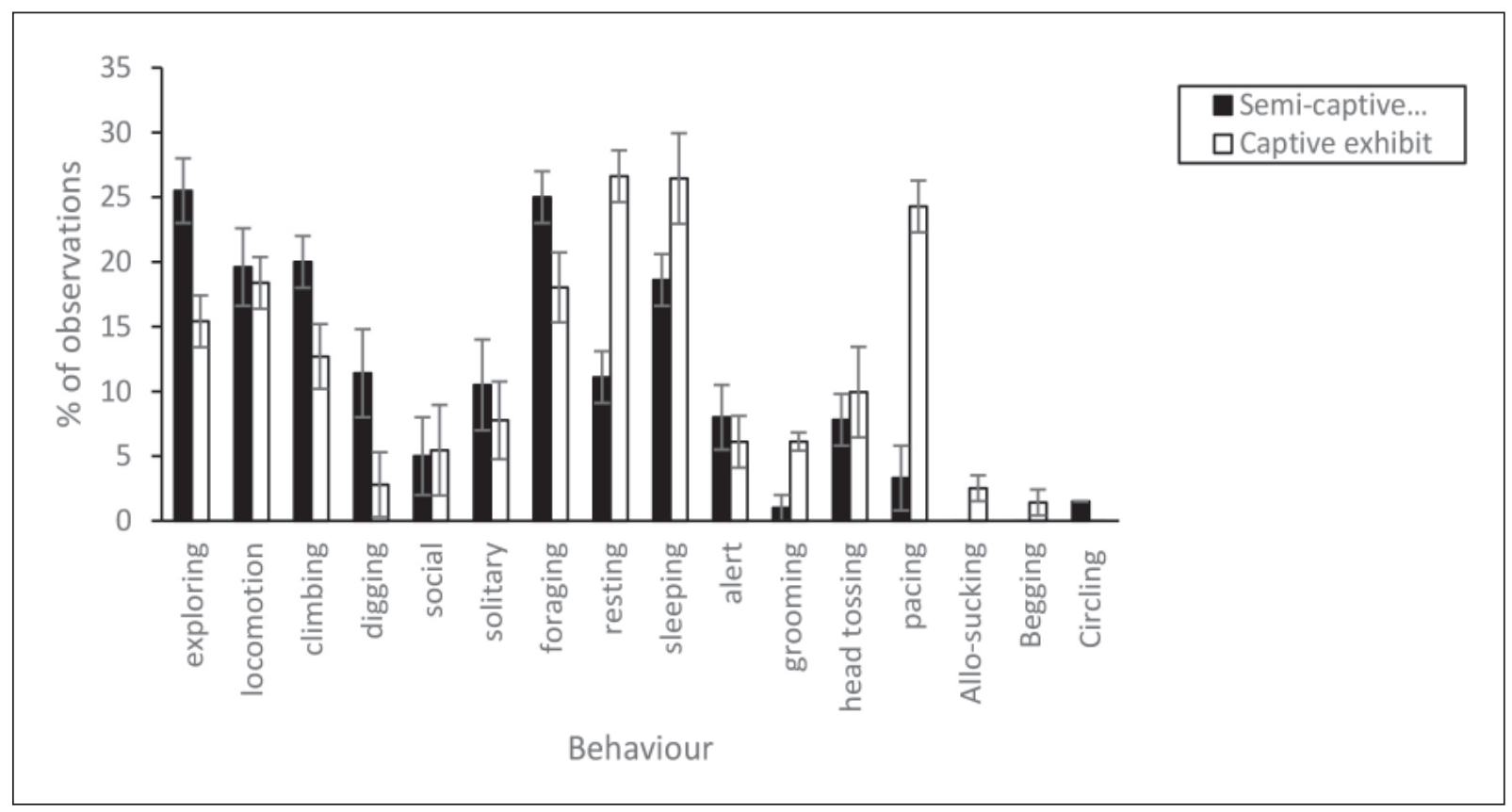

Fig. 1. Mean percentage of observations of all behaviours for captive sun bears across study sites $\left({ }^{*} p<0.05\right.$, Mann-Whitney U).

as pacing, have become common in many species, including bears (Swaisgood \& Shepherdson, 2005; Liu et al., 2006; Tan et al., 2013; Shih et al., 2016). This is because of the barren or unexciting environment (Carlstead \& Shepherson, 2000; Morgan $\&$ Tromborg, 2007). Also, the bears have no opportunity to explore and forage (Carlstead \& Shepherson, 2000; McPhee \& Carlstead, 2010).

For male bears, semi-captive bears were more active as they do more foraging than captive sun bears $(t=3.52, p<0.005)$. This outcome is supported by Carlstead et al. (1991), which stated that wild bears spent considerable portions of their time foraging using complex foraging patterns, such as digging, sucking, tearing, slapping, stabbing, climbing, or turning over objects. Besides, Wong et al. (2004) also recorded that free-ranging male bears were constantly searching for food while walking with their head pointing down the ground and nose sniffing debris on the floor. Meanwhile, captive male bears perform more stereotypic pacing compared to semi-captive sun bears $(t=2.07, p<0.005)$ (Figure 2$)$.

Differences in the proportion of active, passive, and abnormal behaviour were also analysed for captive (Lok Kawi Wildlife Park) and semi-captive bears (Borneon Sun Bear Conservation Centre) (Figure 3). Overall, the bears were significantly more active in the semi-captive than the captive exhibit (Mann-Whitney U, $t=2.75, p<0.005$ ). Significantly more passive behaviours were shown by bears in the captive than the semi-captive exhibit $(t=3.46$, $p<0.005)$. Significantly more stereotypic behaviours occurred in the captive exhibit than in the semicaptive $(t=2.98, p<0.005)$.
For active behaviours (Figure 4), all the behaviours occurred more frequently in the semicaptive than in the captive exhibit (Mann-Whitney $\mathrm{U}, t=3.45, p<0.005)$. In contrast, for passive behaviour (Figure 5), except for alert, captive bears present significantly more passive activities compared to semi-captive bears $(t=2.40, p<0.005)$. Meanwhile, for abnormal behaviour, stereotypic pacing occurred at a significantly higher level in the captive bears (Figure 6) compared to semi-captive bears $(t=3.69$, $p=0.0028)$. Stereotypic pacing has been reported as the most commonly seen behavioural pacing performed by captive bears as they failed to perform their natural foraging and hunting habits (Shih et al., 2016). Stereotypic behaviour, such as pacing, is highly related to stress in animals, especially in bears (Montaudouin \& Le Pape, 2004; Mason et al., 2007). Therefore, it is very important to ensure that stereotypic behaviour in both captive and semicaptive sun bear is minimal. This can be achieved by conducting a further study on activities that bears can perform in the exhibit, such as environmental enrichment; environmental enrichment could simultaneously reduce the stereotypic and abnormal repetitive behaviours and enhance the well-being of zoo animals (Calrstead et al., 1991; Kuczaj et al., 2002; Mason et al., 2007).

\section{Behavioural rhythms of captive and semi-captive sun bear \\ The behavioural rhythms of the sun bear in the} captive exhibit show two peaks of abnormal and passive activities $(\mathrm{H}=4.3, \mathrm{DF}=15, p<0.05)$ (Figure 7). For abnormal activity, the peak was during the 


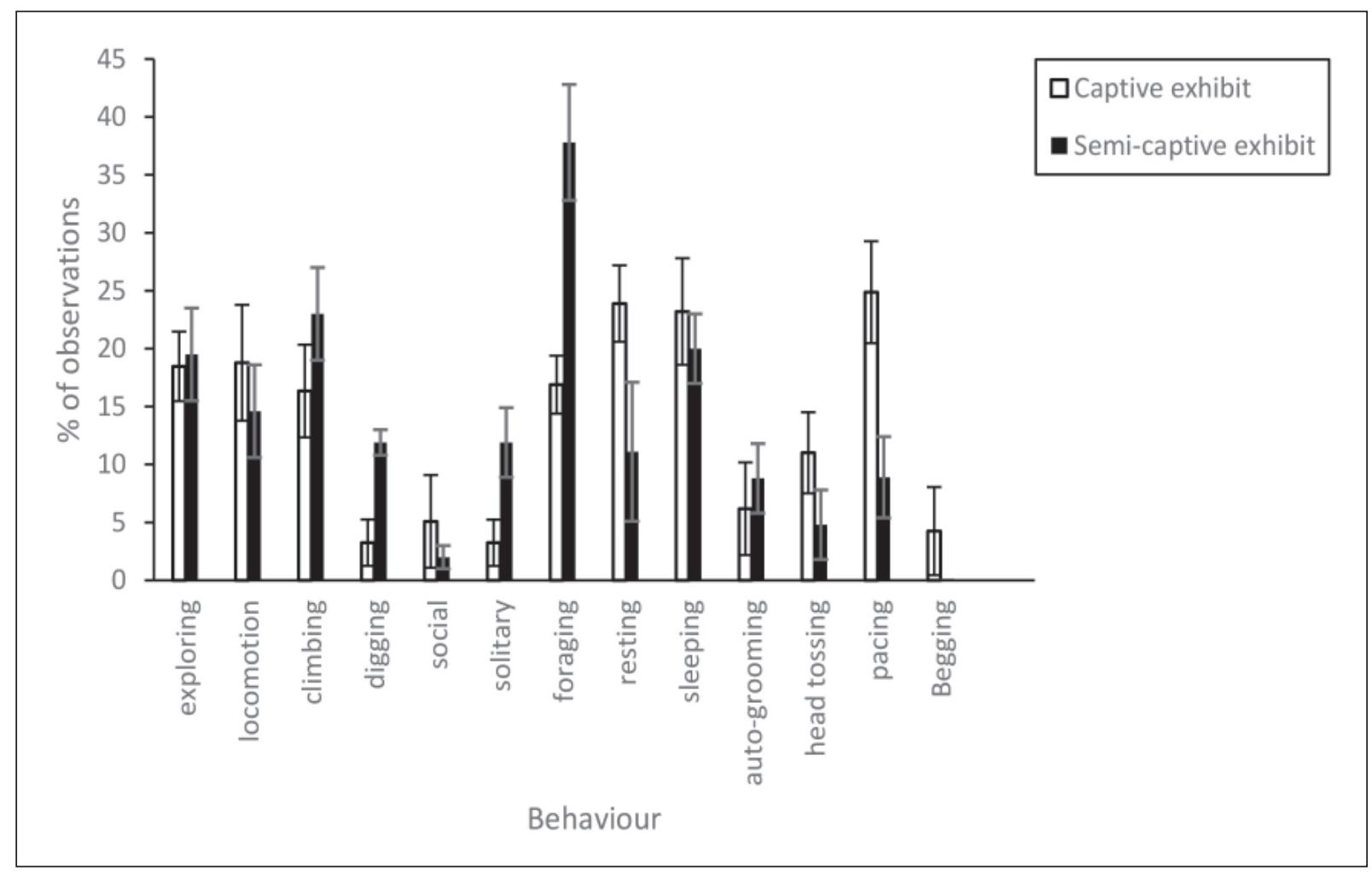

Fig. 2. Mean percentage of observations of all behaviours for male captive sun bears across study sites $\left({ }^{*} p<0.05\right.$, MannWhitney U).

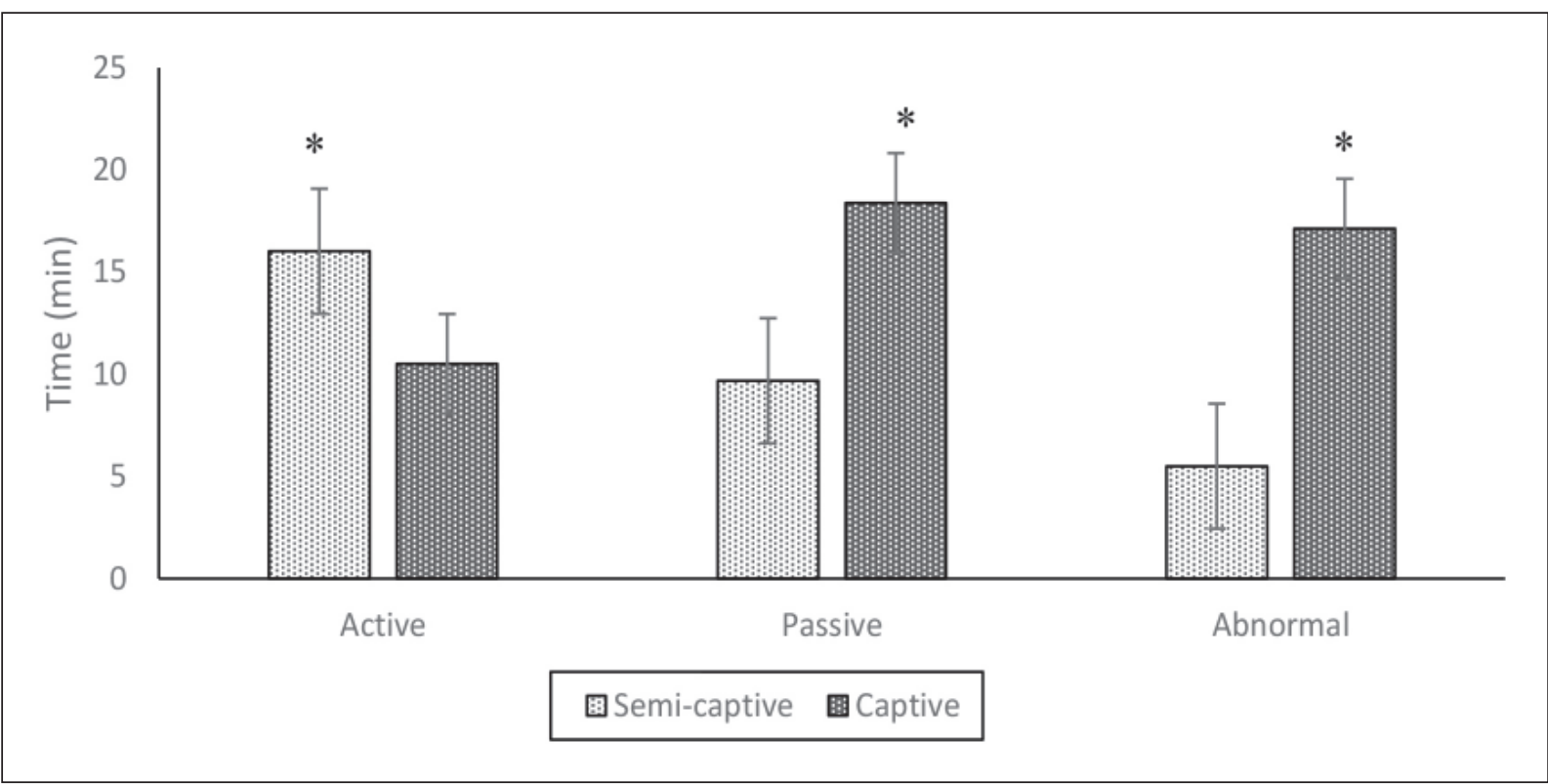

Fig. 3. Activity budget pooled for all individuals in each study site $\left({ }^{*} p<0.05\right.$, Mann-Whitney $\left.\mathrm{U}\right)$.

morning at 1000 to $1059 \mathrm{hr}$, while for passive behaviour, the peak was in the afternoon. This is because in the morning, around 0900 to $1059 \mathrm{hr}$, the bears are actively foraging for food is available around the exhibit. As the food depleted, the bears started to show pacing behaviour. Abnormal activities increase exponentially from afternoon to evening because, in the evening, no more food was provided to the bears in the exhibit; therefore, more pacing behaviour occurs near the door next to the night den. Besides, during this time, the bears are ready to enter their night den, whereby they will be 


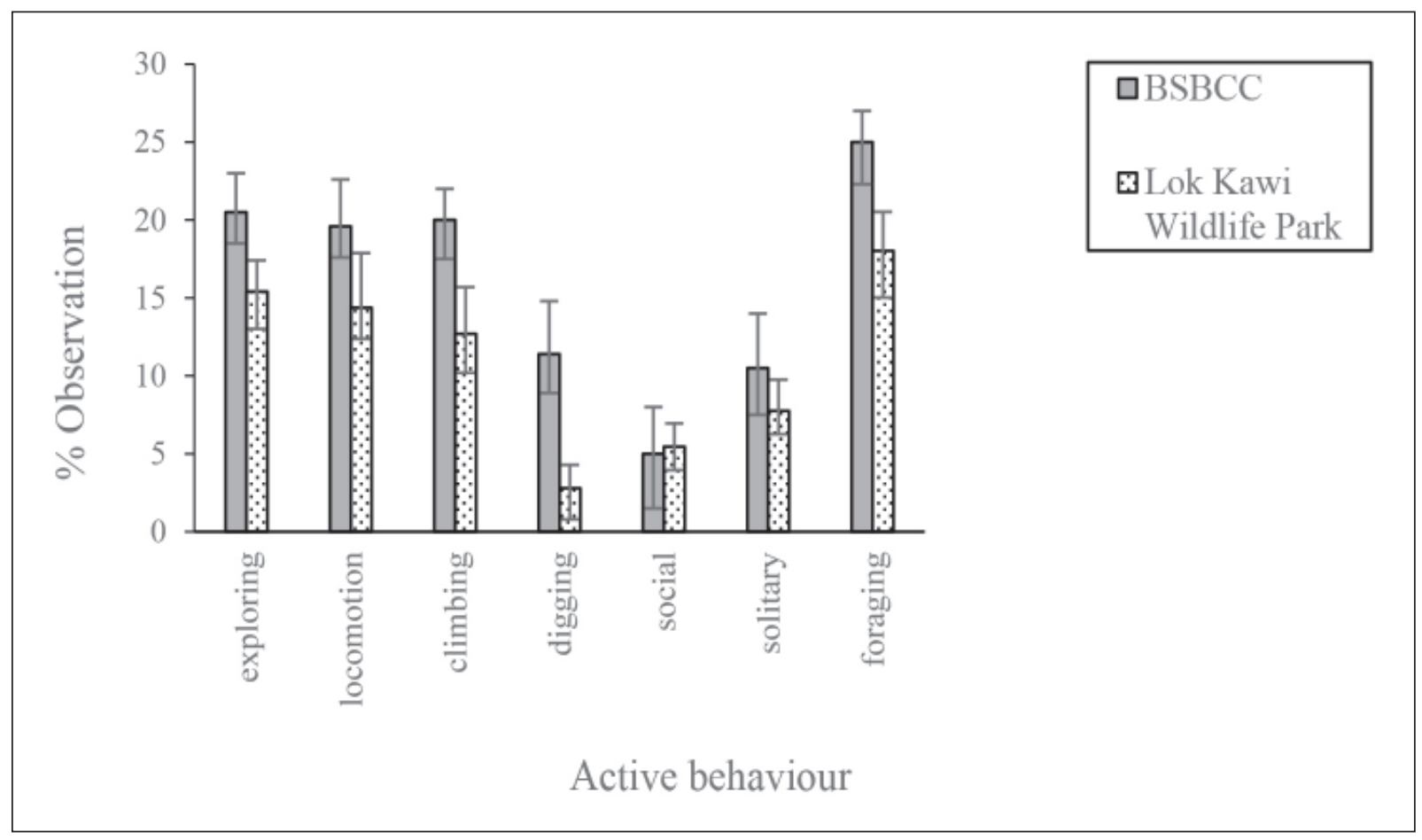

Fig. 4. Mean percentage of observations of active behaviour for sun bear across the study sites.

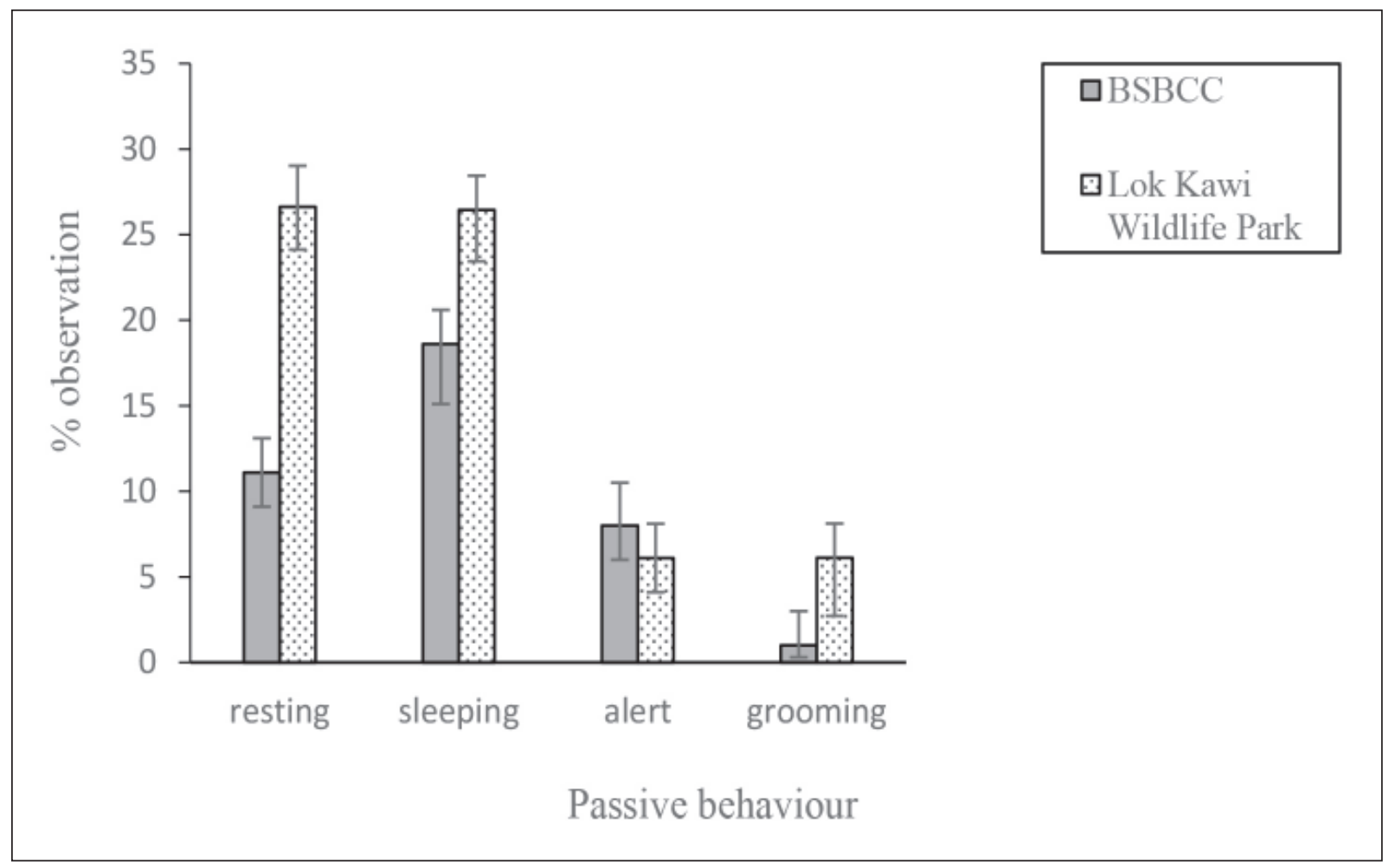

Fig. 5. Mean percentage of observations of passive behaviour for sun bear across the study sites.

provided with food in the den. Meanwhile, in the afternoon, most of the bears were resting and sleeping, leading to decreased active and abnormal behaviours.
In the semi-captive exhibit, one peak in passive behaviour occurred at $1300 \mathrm{hr}(\mathrm{H}=3.6, \mathrm{DF}=15, p<0.05)$ (Figure 8). This happens as most of the bears were sleeping during this time, and some were resting on 


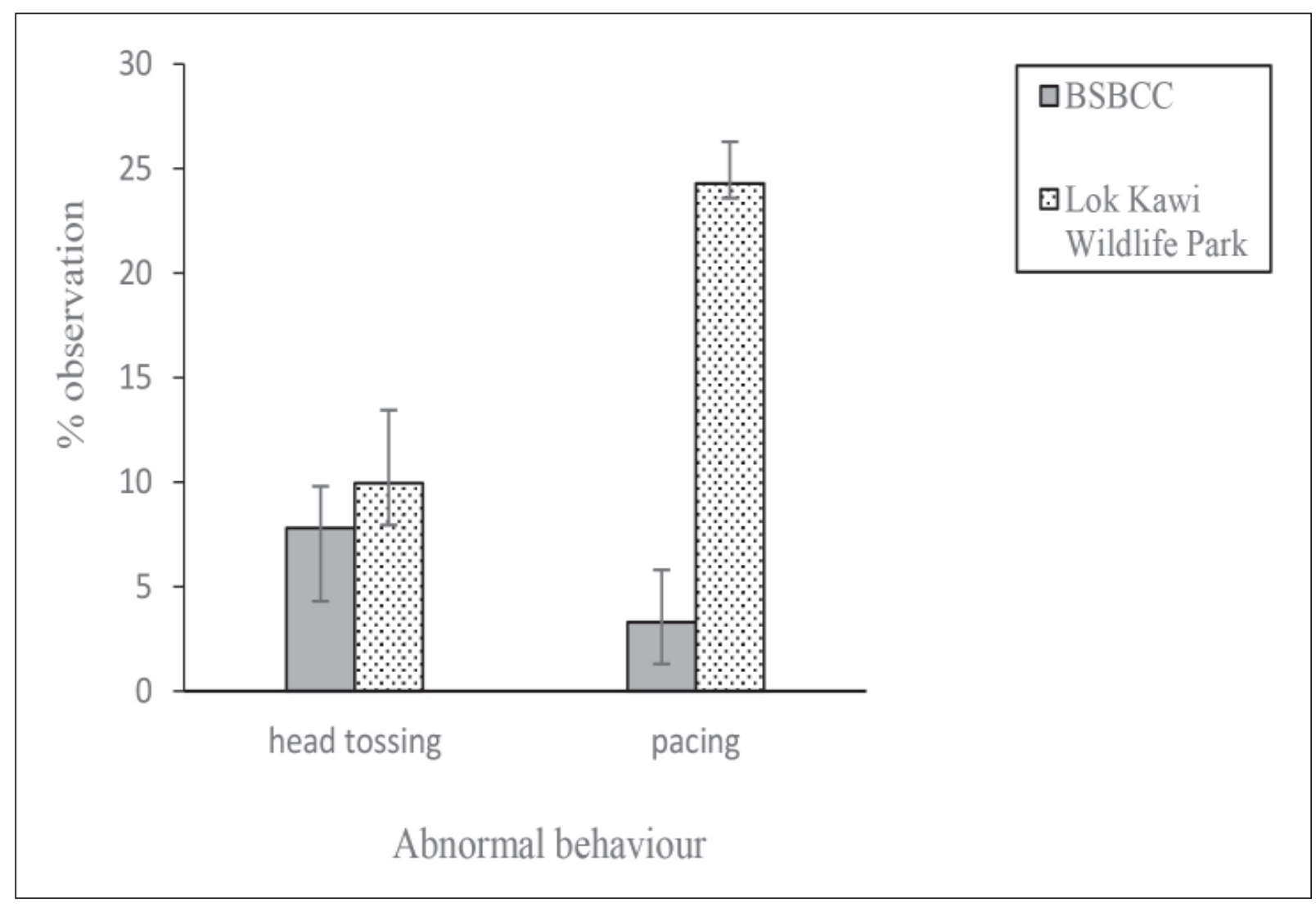

Fig. 6. Mean percentage of observations of abnormal behaviour for sun bear across the study sites.

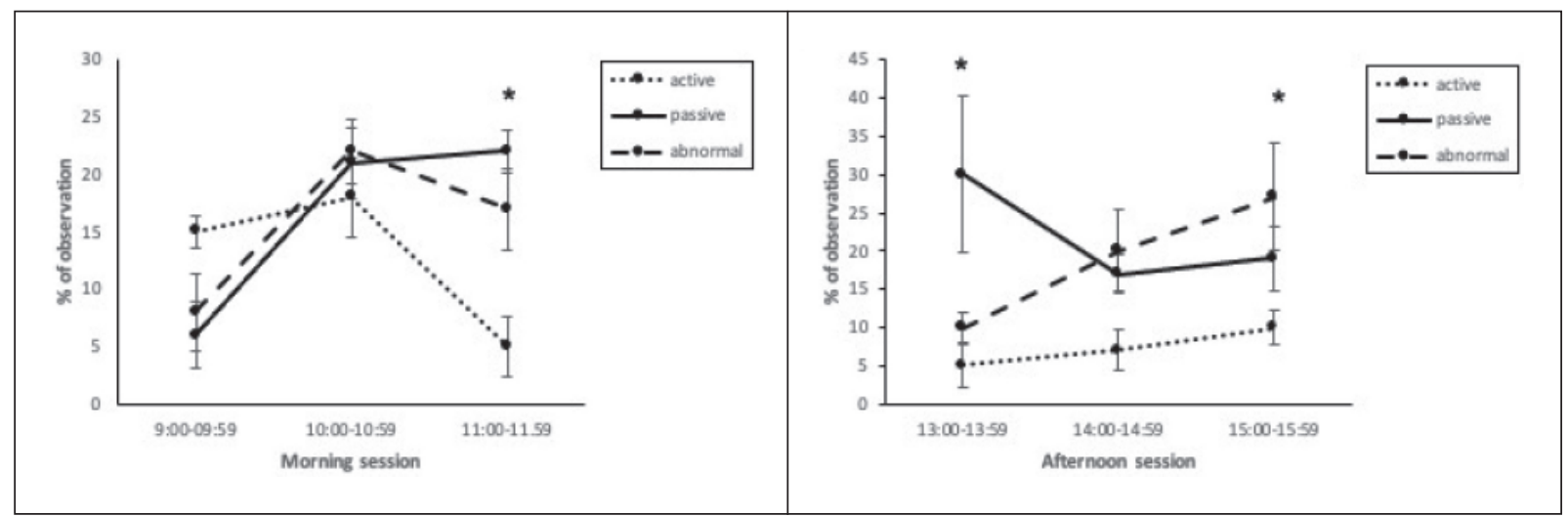

Fig. 7. Mean percentage of observations of behaviours ( \pm 1 SE) for captive sun bears in Lok Kawi Wildlife Park and time of day $(* p<0.05$, Kruskal Wallis $\mathrm{H})$.

the tree. Abnormal behaviour accelerates by the hour and reaches the highest point in the evening. In the evening, all bears started to show pacing behaviour as they were waiting for the door of their night den (which contains food) to be opened.

The active behavioural rhythm for both study sites was almost the same (Figure 9). Active behaviours decreased from morning to noon at both study sites and accelerated in the evening at the captive exhibit. There was no significant difference in the proportion of time spent in active behaviour between captive and semi-captive exhibits (MannWhitney $\mathrm{U} ; t=2.11, p>0.05)$.

There were two peaks in passive behaviour in the captive exhibit (Figure 10). Passive levels peaked at 1000 and $1300 \mathrm{hr}$, while in the semi-captive exhibit, the highest proportion of passive behaviour was exhibited at $1300 \mathrm{hr}$. The result revealed that both study sites have a symmetrical pattern of passive behaviour even though the observation percentage was higher in Lok Kawi Wildlife Park than BSBCC. There was no significant difference in the proportion 


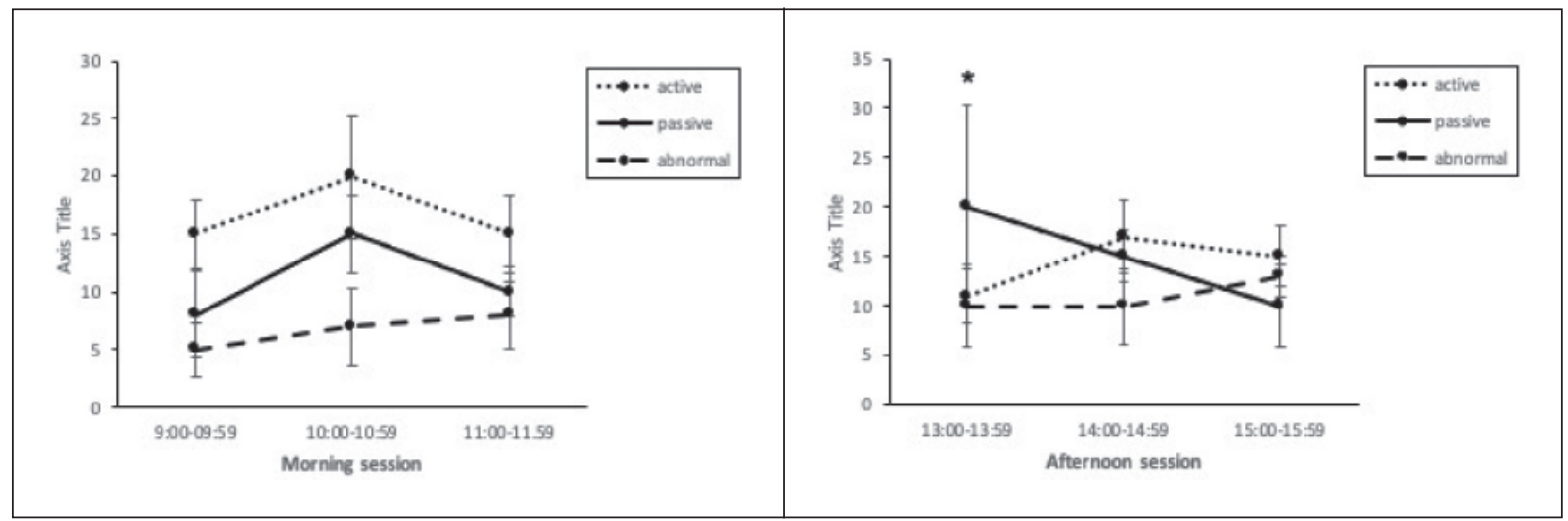

Fig. 8. Mean percentage of observations of behaviours ( $\pm 1 \mathrm{SE})$ for semi-captive sun bears in BSBCC and time of day.

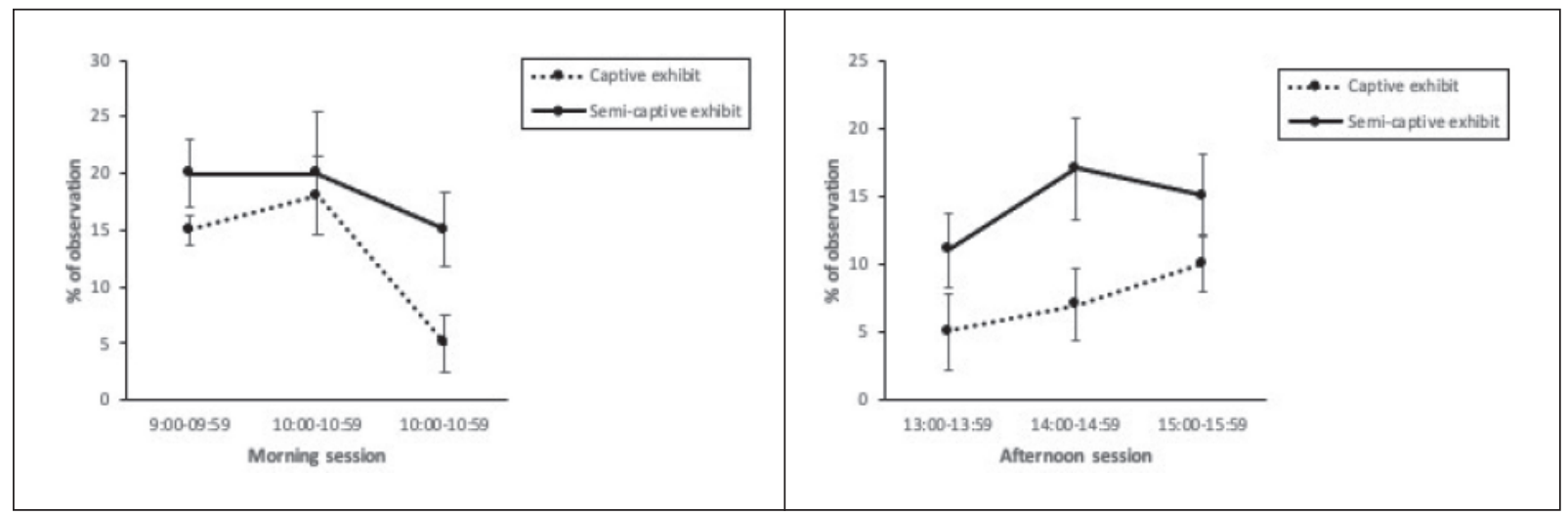

Fig. 9. Mean percentage of observations of active behaviours ( $\pm 1 \mathrm{SE})$ for captive sun bears across study sites and time of day $\left({ }^{*} p<0.05\right.$, Kruskal Wallis).

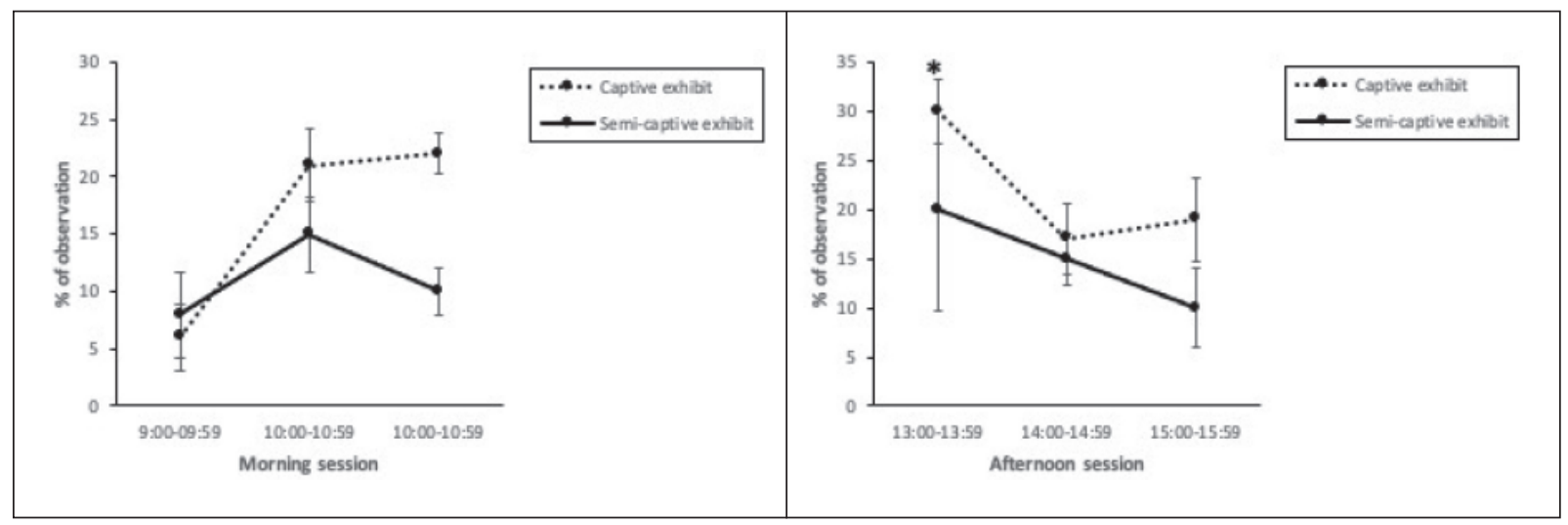

Fig. 10. Mean percentage of observations of passive behaviours ( $\pm 1 \mathrm{SE}$ ) for captive sun bears across study sites and time of day $\left({ }^{*} p<0.05\right.$, Mann-Whitney $\left.\mathrm{U}\right)$.

of time spent in passive behaviour between the barren and naturalistic exhibits $(t=1.62, p>0.05)$.

The proportion of abnormal behaviour peaked during the 1000 and $1400 \mathrm{hr}$ in the captive exhibit, and no peak occurs in the semi-captive exhibit (Figure 11). There were significantly more abnormal behaviours displayed in the captive exhibit than in the semi-captive exhibit $(t=6.01, p<0.05)$.

\section{CONCLUSION}

The semi-captive bear are more active than captive because there are many activities in their exhibit, such as foraging, climbing and resting on a tree. On the other hand, captive sun bears are more passive and did a lot of stereotypic pacing. This concievably because these bears cannot do many activities in 


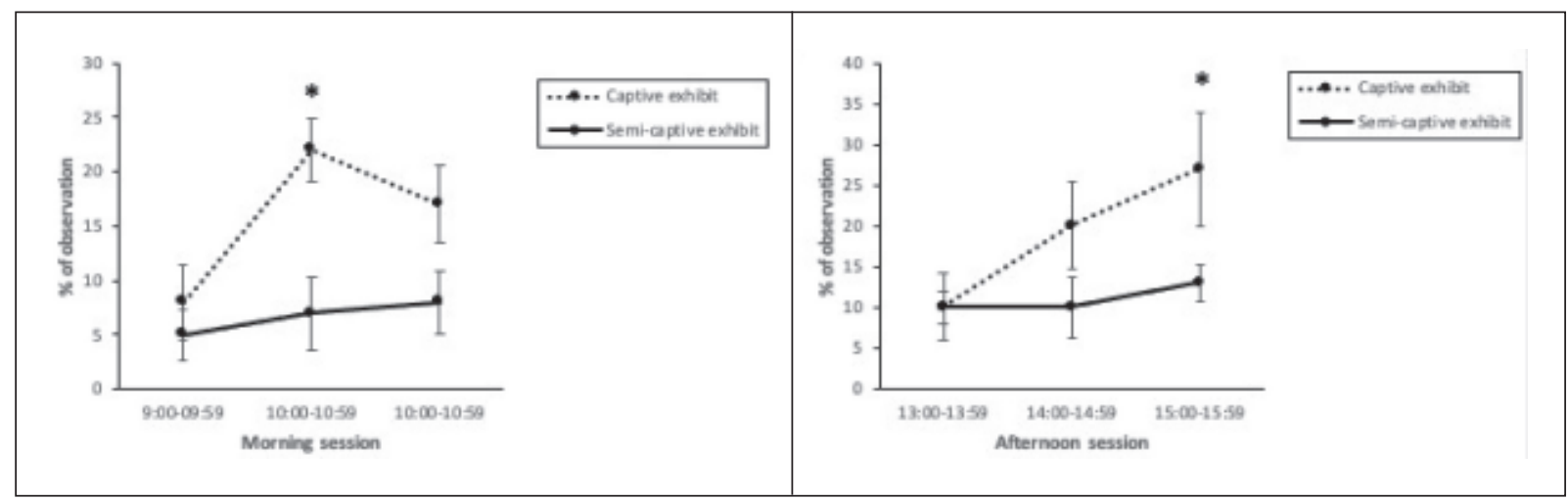

Fig. 11. Mean percentage of observations of abnormal behaviours ( \pm 1 SE) for captive sun bears across study sites and time of day $(* p<0.05$, Mann-Whitney $\mathrm{U})$.

their exhibit as less environmental enrichment was introduced to them. Therefore, it is crucial to introduce more activities, such as an enrichment programme, to the captive bears, to alleviate the abnormal pacing behaviour.

\section{ETHICAL APPROVAL}

The protocol used in this study was approved by the Animal Care and Use Committee of the University of Malaya with the reference no of S/03022020/06122019-01/R.

\section{ACKNOWLEDGEMENT}

The authors would like to thank all staff at Lok Kawi Wildlife Parks and Borneon Sun Bear Conservation Centre for their assistance throughout this study and to Sabah Wildlife Department for granting us a research permit to conduct this study. This research was partially funded by a research grant from the FRGS fund (FRGS/1/2019/WAB13/UiTM/02/1).

\section{REFERENCES}

Altmann, J. 1974. Observational study of behaviour: Sampling methods. Behaviour, 49: 227-267.

Amato, K.R., Belle, S.V. \& Wilkinson, B. 2013. A comparison of scan and focal sampling for the description of wild primate activity, diet and intragroup spatial relationships. Folia Primatology, 87-101.

Berghammer, E.L. 2008. Effects of Enclosure Design on The Behaviour and Physiology of The Captive Grizzly Bear (Ursus arctos horribilis) (Master). ProQuest Dissertations Publishing.
Bluman, A. 2014. Elementary Statistics, A Step by Step Approach. 9th Ed. McGraw-Hill Education, New York.

Carlstead, K., Seidensticker, J. \& Baldwin, R. 1991. Environmental enrichment for zoo bears. Zoo Biology, 10: 3-16.

Carlstead, K. \& Shepherson, D. 2000. Alleviating stress in zoo animals with environmental enrichment. Cabi Publishing. pp. 337-354.

Clubb, R. \& Mason, G.J. 2007. Natural behavioural biology as a risk factor in carnivore welfare: How analysing species differences could help zoos improve enclosures. Applied Animal Behaviour Science, 102: 303-328.

Kuczaj, S., Lacinak, T., Trone, M., Solangi, M. \& Ramos, J. 2002. Keeping environmental enrichment enriching. International Journal of Comparative Psychology, 15(2): 127-137.

Lahdenpera, M., Mar, K.U., Courtiol, A. \& Lummaa, V. 2018. Differences in age-specific mortality between wild-caught and captive-born Asian elephants. Nature Communications, 9: 1-10.

Liu, J., Chen, Y., Guo, L., Gu, B., Liu, H., Hou, A., Liu, X., Sun, L. \& Liu, D. 2006. Stereotypic behavior and fecal cortisol level in captive giant pandas in relation to environmental. Zoo Biology, 25: 445-459.

Mason, G.J. 1991. Stereotypies: A critical reviews. Animal Behaviour, 41(6): 1015-1038.

Mason, G., Clubb, R., Latham, N. \& Vickery, S. 2007. Why and how should we use environmental enrichment to tackle stereotypic behaviour? Applied Animal Behaviour Science, 102: 163 188.

McPhee, M.E. \& Carlstead, K. 2010. The Importance of Maintaining Natural Behaviours in Captive Mammals. Wild Mammals in Captivity. $2^{\text {nd }}$ Ed. University of Chicago Press, Illinois. pp. 303-313. 
Montaudouin, S. \& Le Pape, G. 2004. Comparison of the behaviour of European brown bears (Ursus arctos arctos) in six different parks, with particular attention to stereotypies. Behavioural Processes, 67(2): 235-244.

Morgan, K.N. \& Tromborg C.T. 2007. Sources of stress in captivity. Applied Animal Behaviour Science, 102: 262-302.

Robeck, T.R., Willis, K., Scarpuzzi, M.R. \& O’Brien, J.K. 2015. Comparisons of life-history parameters between free-ranging and captive killer whale (Orcinus orca) populations for application toward species management. Journal of Mammalogy, 96(5): 1055- 1070.

Shepherdson, D., Lewis, K.D., Carlstead, K., Bauman, J. \& Perrin, N. 2013. Individual and environmental factors associated with stereotypic behaviour and fecal glucocorticoid metabolite levels in zoo housed polar bears. Applied Animal Behaviour Science, 147: 268-277.

Shih, H-Y., Yu, J-F. \& Wang, L-C. 2016. Stereotypic behaviours in bears. Taiwan Veterinary Journal, 42(1): 1-7.

Stokes, J. 2014. Observation in Behavioural Patterns of Bornean Sun Bears Helarctus malayanus euryspilus in Rehabilitation Center Tropical Rainforest Reserve in Sabah, Borneo (Thesis). Oregon State University.
Swaisgood, R.R. \& Shepherdson, D.J. 2005. Scientific approaches to enrichment and streotypies in zoo animal: What's been done and where should we go next?. Zoo Biology, 24(6): 499-518.

Tan, H.M., Ong, S.M., Langat, A.R., Sharma, R.S.K. \& Sumita, S. 2013. The influence of enclosure design on diurnal activity and streotypic behaviour in captive Malayan Sunbears (Helacrtos malayanus). Research in Veterinary Science, 94: 228-239.

Veeraselvam, M., Sridhar, R., Jayathangaraj, M.G. \& Perumal, P. 2013. Behavioural study of captive sloth bearsusing environmental enrichment tools. International Journal of Zoology, 2013: 526905.

Vickery, S.S. \& Mason, G.J. 2005. Stereotypy and perseverative responding in caged bears: Further data and analyses. Applied Animal Behaviour Science, 91: 247-260.

Wolfensohn, S., Shotton, J., Bowley, H., Davies, S., Thompson, S. \& Justice, W.S.M. 2018. Assessment of welfare in zoo animals: Towards optimum quality of life. Animal, 8(110): 1-16.

Wong, S.T., Servheen, C. \& Ambu, L. 2004. Home range, movement and activity patterns, and bedding sites of Malayan sun bears, Helarctos malayanus in the rainforest of Borneo. Biological Conservation, 119: 168-181. 